\title{
Characterization of Strong and Crystalline Polyvinyl Alcohol/Montmorillonite Films Prepared by Layer-by-Layer Deposition Method
}

\author{
S. Gaidukov, ${ }^{1}$ I. Danilenko, ${ }^{1}$ and G. Gaidukova ${ }^{2}$ \\ ${ }^{1}$ Institute of Polymer Materials, Riga Technical University, 14/24 Azenes Street, Riga LV-1048, Latvia \\ ${ }^{2}$ Institute of Applied Chemistry, Riga Technical University, 14/24 Azenes Street, Riga LV-1048, Latvia \\ Correspondence should be addressed to S. Gaidukov; gaidukov@gmail.com
}

Received 14 January 2015; Revised 24 February 2015; Accepted 6 March 2015

Academic Editor: Wen Shyang Chow

Copyright (c) 2015 S. Gaidukov et al. This is an open access article distributed under the Creative Commons Attribution License, which permits unrestricted use, distribution, and reproduction in any medium, provided the original work is properly cited.

\begin{abstract}
The preparation of a high-strength and highly crystalline nanocomposite with a layered structure by the use of layer-by-layer deposition (LbL) method from polyvinyl alcohol (PVOH) and montmorillonite (MMT) platelets is reported. The crystallinity and interactions between the components were studied by the use of Fourier transform infrared spectroscopy (FT-IR), wide angle Xray diffraction (WAXD), differential scanning calorimetry (DSC), and thermogravimetric analysis (TGA). The nanocomposite film structure was investigated by the use of scanning electron microscope (SEM) and atomic force microscopy (AFM). The stiffness of the LbL PVOH/MMT film was significantly higher compared to pure PVOH and conventional PVOH/MMT nanocomposite. The structural and thermal studies on thin PVOH/MMT films indicated the enhanced crystallinity of the polymer.
\end{abstract}

\section{Introduction}

The layer-by-layer (LbL) assembly is a simple method of thin film deposition [1]. It was successfully applied to the preparation of thin composite films combining nanoparticles and polymer. It is simple method to produce from diverseby-nature raw materials high quality coatings and films of highly layered structure with regular coplanar orientation of the components [2]. Other deposition techniques that can be used for preparation of layered films are spin coating, Langmuir-Blodgett deposition, and others [3-5].

Nanocomposites are of scientific interest because of their improved properties due to the nanoparticle application and nanoscale interactions [6]. It was demonstrated that the nanocomposites of polymers and nanoparticles could combine the best properties of the components: deformational properties of polymer matrix and high elasticity and strength of nanoparticles $[7,8]$. It has been also reported that the thermal stability and permeability properties of composites could be greatly improved by the addition of nanoparticles $[9,10]$.
With LbL deposition, multilayer films with different thicknesses and structures can be achieved on the colloids [11] and substrates [12] and also as free films [13]. The use of different reinforcing nanoparticles in polymer matrix has grown exponentially. A variety of nanoparticles (carbon nanotubes, graphene oxide, calcium carbonate, and montmorillonite) and polymers (polyethyleneimine, polyvinyl alcohol) have been used for preparation of layered polymer-nanocomposite films $[8,12-17]$.

One of the most commonly used materials for this purpose is nanoclay or montmorillonite (MMT), in which nanoparticles have platelet geometry [18]. It can be used as reinforcing nanoscale filler in hydrophilic and hydrophobic polymer matrices [18]. Nanoclay particles strong interaction with polymer can develop intercalated or exfoliated nanocomposites $[18,19]$. An initial MMT is characterized by hydrophilicity, which makes it dispersible in water and compatible with hydrophilic polymers. As a result of MMT very high stiffness (modulus of elasticity $E=175 \mathrm{GPa}$ ), it has been widely used as reinforcing filler in polymer films produced by LbL deposition from polyvinyl alcohol (PVOH) 
TABLE 1: MMT characteristics.

\begin{tabular}{lcccccc}
\hline Nanoclay, MMT & 2Theta, deg & $d_{001}, \mathrm{~nm}$ & CEC, Meq/100 g & Specific weight, $\mathrm{g} / \mathrm{cm}^{3}$ & Particle size, nm & Loss in ignition, \% \\
\hline Dellite LVF & 7.0 & 1.26 & 105 & 2.2 & 500 & 4 \\
\hline
\end{tabular}

[20], polyurethane (PU) [21], and polyethylene oxide (PEO) [22]. Such biopolymers as chitosan [23] and heparin [24] can be LbL deposited with addition of MMT. Biologically inspired and nanoscale designed LbL deposited films of MMT and hydrophilic polymer exhibit extremely high stiffness and thermal properties, as well as maintaining its high optical transparency [25-27]. The mechanical properties were found to enhance after sequential deposition of PVOH and MMT layers due to the existence of lamina structure and strong hydrogen bonding interactions between the polymer and nanoplatelets [28]. MMT also modify the crystalline structure of the PVOH [29]. The polymer crystallization occurs in the ultrathin layers (only some nanometers thick). It is strictly affected by macromolecule-nanoparticle interactions. Recently, it has also been reported that electrically conductive and cross-linked films using $\mathrm{PVOH}$ and nanoplatelets can be processed by LbL deposition [30]. They can be used as polymer membranes for fuel cells [31].

The LbL deposition method is very simple technique to prepare polymer nanocomposites with organized structures and enhanced properties. In the present work, we are demonstrating the preparation of very strong and highly crystalline polyvinyl alcohol/montmorillonite (PVOH/MMT) thin films with regular layered structure by LbL deposition. The resulting layered films display remarkable tensile characteristics exceeding the properties of the initial polymer material and conventional polymer-nanoclay nanocomposite. We also explore, by the use of different instruments, the crystallinity degree of the polymer in the LbL film, which differs significantly from the crystalline structure of the bulk PVOH polymer. It is important because the crystalline structure strongly influences the final macromechanical properties of the polymer nanocomposite.

\section{Experimental Details}

2.1. Materials. Dellite LVF, supplied by the Laviosa Chimica Mineraria S.p.A., was used as a $\mathrm{Na}^{+}$montmorillonite (MMT). The characteristic parameters of the used MMT were shown in Table 1. Polyvinyl alcohol (PVOH) with a molecular weight of $133,000 \mathrm{Da}$, acetate group content of $0.98 \%$, and density of $1.28 \mathrm{~g} / \mathrm{cm}^{3}$ was used.

\subsection{LbL Preparation of Layered Thin Films. For LbL prepa-} ration of thin film, room temperature distilled water was used to prepare a suspension of MMT at concentration of $0,5 \mathrm{wt} . \%$. The suspension was stirred for $12 \mathrm{~h}$ and sonicated with Hielscher sonicator for $2 \mathrm{~h}$. The $\mathrm{PVOH}$ powder was mixed with distilled water and then it was heated to about $90^{\circ} \mathrm{C}$ to dissolve the polymer.

Thin film of PVOH/MMT was synthesized by LbL deposition method on a glass substrate [1]. Before the deposition of PVOH/MMT films, the microscope glass slides were immersed into "piranha" solution for 1 hour to remove all possible organic contaminants. "Piranha" solution was the mixture $\mathrm{H}_{2} \mathrm{SO}_{4} / \mathrm{H}_{2} \mathrm{O}_{2}$ with the ratio $3: 1$. It was followed by continuous washing with deionized water and drying.

The PVOH/MMT film preparation was the following: glass slide was immersed in $0.5 \mathrm{wt}$.\% solution of $\mathrm{PVOH}$ for $30 \mathrm{~s}$, washed with distilled water for $1 \mathrm{~min}$ and dried with nitrogen for $1 \mathrm{~min}$, and then immersed in $0.5 \mathrm{wt} . \% \mathrm{MMT}$ water dispersion for $30 \mathrm{~s}$. Accordingly, one double layer was developed. The procedure continued till 130 double layers were received. A free-standing thin film of PVOH/MMT was detached from the substrate for further examinations.

Two additional samples were prepared to compare the results: pure $\mathrm{PVOH}$ film and $\mathrm{PVOH} / \mathrm{MMT}^{*}$ traditional nanocomposite. Film of pure PVOH was prepared by polymer solution casting in a $100 \mathrm{~mm}$ diameter polystyrene Petri dish. It was dried in oven at $60^{\circ} \mathrm{C}$ for $48 \mathrm{~h}$. PVOH/MMT ${ }^{*}$ nanocomposite with MMT loading of $3 \mathrm{wt} . \%$ was prepared by a solution-intercalation casting method. $\mathrm{PVOH}$ was dissolved in the MMT water dispersion, and solution was sonicated for $60 \mathrm{~min}$. The prepared films were kept in closed dish over the dried $\mathrm{KBr}$ powder until testing.

2.3. Investigation Methods. Atomic force microscopy (AFM) images of PVOH/MMT thin film surface were obtained using a CP II Scanning Probe Microscope from Veeco Instruments. The instrument was operated in tapping mode with $\mathrm{SiN}_{3}$ cantilever tips (Veeco Nanoprobes) at a scan rate of $1 \mathrm{~Hz}$.

The surface and the cross section of the PVOH/MMT film were examined with a scanning electron microscope (SEM) Tescan, Mira//LMU Schottky, at different magnifications and a voltage of $25 \mathrm{kV}$. The surfaces were covered with gold (Emitech, K550X).

The wide angle X-ray diffraction (WAXD) measurements were carried out to evaluate the layered structure of the film. They were obtained on a Panalitical X'Pert PRO diffractometer at a temperature of $20^{\circ} \mathrm{C}$. The monochromatic irradiation of $\mathrm{CuK}_{\alpha}$ with a wavelength of $\lambda=0.154 \mathrm{~nm}$ in the range of diffraction angles 2theta from 2 to $40 \mathrm{deg}$ was used. The voltage was $40 \mathrm{kV}$ and the scanning rate $0.125 \mathrm{deg} / \mathrm{s}$. Diffraction patterns were analyzed by the use of software FITYK-093. Crystallinity $\chi^{\text {WAXD }}$ was calculated by $[32,33]$

$$
\chi^{\mathrm{WAXD}}(\%)=100 \% \times \frac{A_{c}}{\left(A_{c}+A_{a}\right)},
$$

where $A_{a}$ is experimental integrated intensity of amorphous phase and $A_{c}$ is experimental integrated intensity of crystalline phase.

FT-IR spectra were collected at a resolution of $4 \mathrm{~cm}^{-1}$ on a Bruker VERTEX 80 FT-IR spectrometer in the region of $500-4000 \mathrm{~cm}^{-1}$. The FT-IR absorption bands were used to study the interactions of the components and to calculate the 
TABLE 2: Characteristic temperatures, crystallinity, and mechanical properties of PVOH, PVOH/MMT, and PVOH/MMT* films.

\begin{tabular}{lcccccccc}
\hline & $T_{d}$ & $T_{m}$ & $\chi^{\text {DSC }}$ & $\chi^{\text {WAXD }}$ & $\chi^{\text {FTIR }}$ & $\begin{array}{c}E \\
\text { GPa }\end{array}$ & $\begin{array}{c}\sigma \\
\text { MPa }\end{array}$ & $\%$ \\
& ${ }^{\circ} \mathrm{C}$ & ${ }^{\circ} \mathrm{C}$ & $\%$ & $\%$ & $\%$ & 48.7 & 1.9 & 85.1 \\
PVOH & 315.0 & 226.5 & 44.9 & 52.4 & 69.1 & 11.2 & 150.2 \\
PVOH/MMT & 279.3 & 273.1 & 85.3 & 77.0 & n.a. & 3.2 & 8.2 \\
PVOH/MMT & n.a. & n.a. & n.a. & n.a. & & 3.2 \\
\hline
\end{tabular}

crystallinity degree of the polymer. Spectra were measured in reflection and transmittance modes with the mercuric cadmium telluride (MCT) detector cooled with the liquid nitrogen. 16 measurements for every sample were performed and averaged spectrum was shown. Spectral data were analyzed by the use of original software Image v.2.2 and Spectrum v.2. Degree of crystallinity was obtained using the previously reported method proposed by Peppas and [34-37]

$$
\chi^{\mathrm{FTIR}}(\%)=a+b\left(\frac{A_{c}}{A_{a}}\right)
$$

where $A_{c}$ is experimental intensity of the crystallinity band at $1142 \mathrm{~cm}^{-1} ; A_{a}$ is experimental intensity of the crystallinity band at $1432 \mathrm{~cm}^{-1} ; a$ and $b$ are constants which were calculated using values of the degrees of crystallinity.

The calorimetric tests were carried out on a Mettler DSC1 instrument. Specimens about $10 \mathrm{mg}$ in weight were scanned in heating mode, by using nitrogen as a purge gas in the temperature range from 25 to $300^{\circ} \mathrm{C}$. The DSC ran at a rate of $10^{\circ} \mathrm{C} / \mathrm{min}$. The melting enthalpy and temperature $T_{m}$ were calculated from the experimental heating curves. Degree of crystallinity was calculated from $[32,38]$

$$
\chi^{\mathrm{DSC}}(\%)=\frac{\Delta H_{\exp }}{\Delta H_{100 \%}},
$$

where $\Delta H_{\exp }$ is experimental melting enthalpy of crystalline phase, J/g; $\Delta H_{100 \%}$ is theoretical melting enthalpy of $\mathrm{PVOH}$ crystalline phase, $138.7 \mathrm{~J} / \mathrm{g}$ [39].

The PVOH and PVOH/MMT thermal stability and the content of MMT were evaluated from the weight-loss heating curves from within a thermogravimetric analysis (TGA). The TGA tests were performed on a Mettler TG50 instrument. Specimens of about $10 \mathrm{mg}$ in weight were heated in air up to $800^{\circ} \mathrm{C}$. The degradation temperature $T_{d}$ and weight loss were calculated, according to ASTM D3850, by using the Mettler original software.

The mechanical properties were analyzed by the use of universal tester Zwick BDO. The uniaxial tension was carried out under ambient conditions according to EN ISO 527. The specimens of rectangular strip shape, length $30 \mathrm{~mm}$ and width $3 \mathrm{~mm}$, were stressed at constant crosshead rate of $1 \mathrm{~mm} / \mathrm{min}$, which is equal to the start deformation speed of $3 \% / \mathrm{min}$. More than five parallel samples were tested. The error of the measurements was about $20 \%$. The elastic modulus $E$ was calculated from the stress-strain curves tangent at the beginning of the coordinate axis.



FIGURE 1: TGA heating curves of PVOH and PVOH/MMT film.

\section{Results and Discussion}

TGA was performed to evaluate the thermal properties and the weight loss of the specimens. Figure 1 showed the TGA curves of $\mathrm{PVOH}$ and $\mathrm{PVOH} / \mathrm{MMT}$ films. The degradation temperature $T_{d}$ for $\mathrm{PVOH}$ was $315^{\circ} \mathrm{C}$. It decomposed very fast starting at $250^{\circ} \mathrm{C}$. PVOH/MMT characterized the decrease of $T_{d}$ till $279^{\circ} \mathrm{C}$ (see Table 2 ). It was established from TGA weight loss curves that heating the PVOH/MMT to $600^{\circ} \mathrm{C}$ decreases its weight by about $50 \%$. The observed initial decrease in the weight of the nanocomposite could be connected to the some residual water vaporization and in the range of $300-600^{\circ} \mathrm{C}$ was also caused by decomposition of the polymer $[18,40,41]$.

The layered structure of the film was testified by the use of WAXD. Figure 2 showed the WAXD pattern of pure PVOH, MMT, and PVOH/MMT film with 30, 80, and 130 double layers. The diffractogram curve of initial MMT contained a clear characteristic diffraction peak at 2Theta $=7.0 \mathrm{deg}$, which was caused by the MMT layers periodicity and corresponded to the basic or interlayer distance $d_{001}=$ $1.26 \mathrm{~nm}$ (Table 1). Diffraction peak of layered structure of the film PVOH/MMT appeared at smaller diffraction angles of 2Theta. It was assumed that, with increased number of the double layers in the film, the characteristic diffraction intensity of layered structure also increased correspondingly. The interlayer distance $d_{001}$ was about $3.3 \mathrm{~nm}$. Region of 2 Theta $=15-25^{\circ}$ at diffraction pattern was contributed to the diffraction of PVOH crystalline structure. The changes in the 


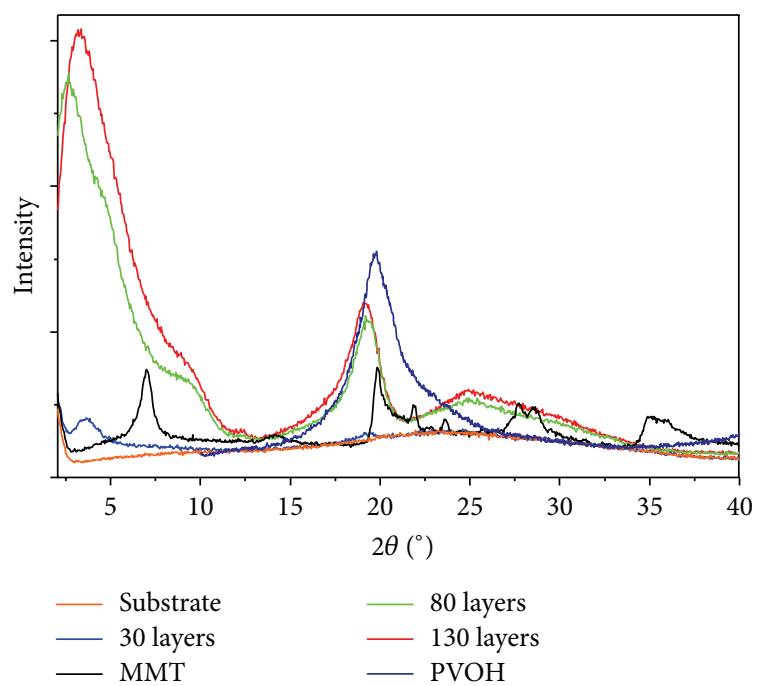

FIGURE 2: X-ray diffraction pattern of MMT and PVOH/MMT film after 30, 80, and 130 double layers deposition.

intensity and the shape of the peaks revealed the modification of polymer crystal structure. The macromolecular chain mobility could be restricted due to the absorption on MMT layers and development of strong bond interactions [29]. So the PVOH crystallization occurred in the limited space, that is, confined environment $[42,43]$. The degree of crystallinity $\chi^{\text {WAXD }}$ of PVOH was calculated using the method of area under the diffraction curve $[32,33]$. The calculated values were given in Table 2 . The diffraction pattern intensity of the PVOH/MMT crystalline phase was more intensive in comparison to the $\mathrm{PVOH}$, which corresponded also to higher crystallinity values. $\chi^{\text {WAXD }}$ for PVOH was about $52 \% ; \chi^{\text {WAXD }}$ for PVOH/MMT was increased till 77\%. MMT layers possibly acted as nucleating agent changing the overall polymer crystalline structure and amount of crystalline phase [42, 43].

FT-IR spectra were received to characterize the developed interactions between the components. FTIR spectra, measured in the range $500-4000 \mathrm{~cm}^{-1}$ for PVOH, MMT, and PVOH/MMT samples, were shown in Figure 3. For PVA, the characteristic absorption peaks were at $3330-3340 \mathrm{~cm}^{-1}$ (O-H stretching vibration), $2942 \mathrm{~cm}^{-1}$ (C-H stretching vibration), $1430 \mathrm{~cm}^{-1}\left(\mathrm{CH}_{2}\right.$ bending vibration), $1141 \mathrm{~cm}^{-1}$ (C-C and C-O-C stretching vibration), $1096 \mathrm{~cm}^{-1}$ (C$\mathrm{O}$ stretching vibration), $916 \mathrm{~cm}^{-1}\left(\mathrm{CH}_{2}\right.$ rocking vibration), and $850 \mathrm{~cm}^{-1}$ (C-C stretching vibration) [35]. For initial MMT, the characteristic bands were observed at $920 \mathrm{~cm}^{-1}$ (Al-O-H), $796 \mathrm{~cm}^{-1}$ (Al (Mg)-O-H), $1040-1120 \mathrm{~cm}^{-1}$ (Si$\mathrm{O}$ ), and $525 \mathrm{~cm}^{-1}$ and $470 \mathrm{~cm}^{-1}$ (Al (Mg)-O-Si) [44]. The spectrum of $\mathrm{PVOH} / \mathrm{MMT}$ film showed combined peaks in the bands region of the initial components. A broad band in the region $3300-3700 \mathrm{~cm}^{-1}$ (O-H vibration) was observed, which corresponded to the presence of $\mathrm{O}-\mathrm{H}$ groups involved in formation of hydrogen bonding between the components.

FT-IR spectra were also used to characterize the crystallinity degree $\chi^{\mathrm{FTIR}}$ of PVOH and PVOH/MMT (Table 2).

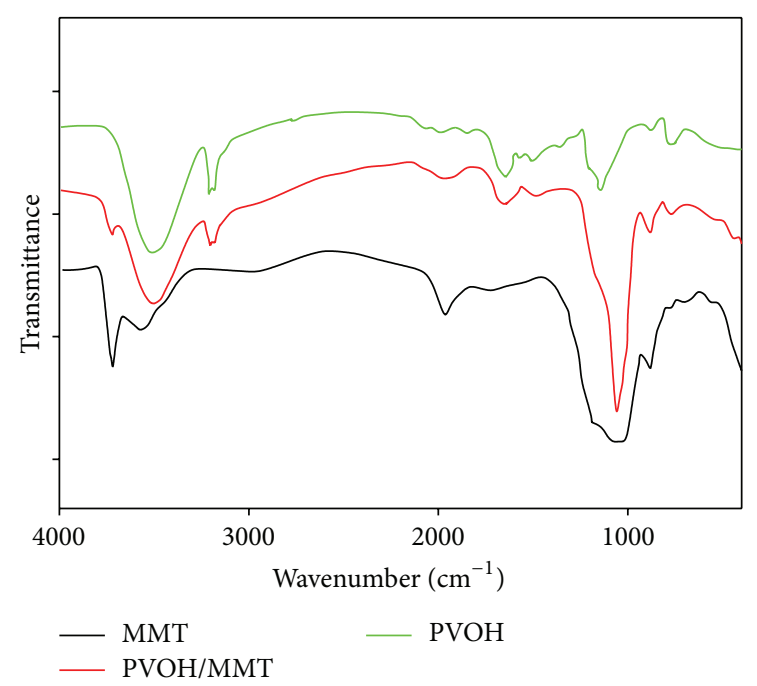

Figure 3: FTIR spectra of PVOH, MMT, and PVOH/MMT film.

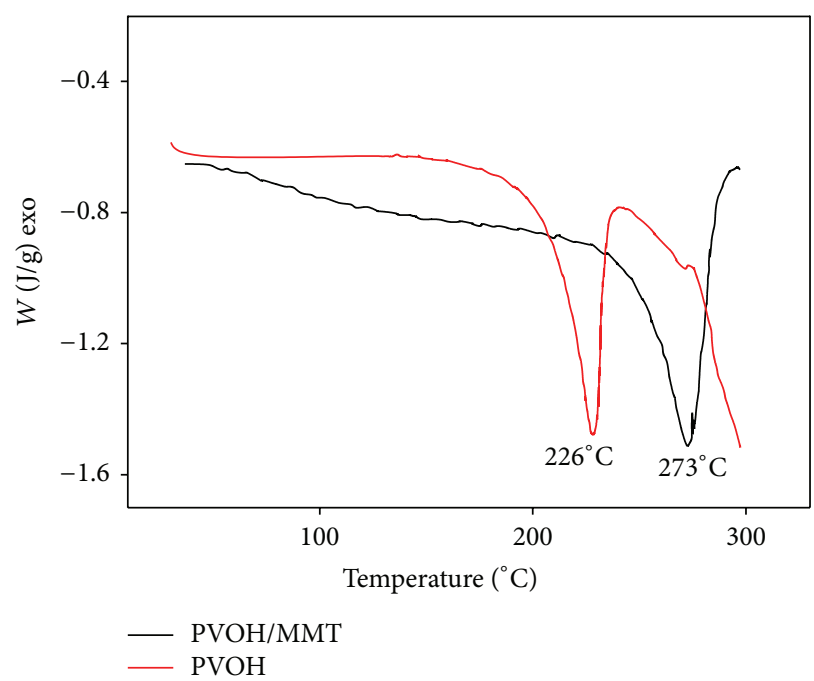

FIGURE 4: DSC heating curves of PVOH and PVOH/MMT film.

We used the ratio of the intensities of absorption bands at $1142 \mathrm{~cm}^{-1}$ and $1432 \mathrm{~cm}^{-1}$ to calculate the degree crystallinity $\chi^{\text {FTIR }}$ [34-37]. It also testified the increase of crystallinity for $\mathrm{PVOH} / \mathrm{MMT}$ and the nucleating effect of MMT $[42,43]$. For PVOH, $\chi^{\text {FTIR }}$ was about $\sim 48 \%$, but for PVOH/MMT $\chi^{\text {FTIR }}=$ $69 \%$.

The results of DSC were presented in Figure 4 as thermograms for the pure PVOH and PVOH/MMT thin film. The heating curves showed broad endotherms at interval 200$300^{\circ} \mathrm{C}$ associated with melting of $\mathrm{PVOH}$ polymer. Melting temperature $T_{m}$ and degree of crystallinity $\chi^{\text {DSC }}$ were calculated from the endotherms and summarized in Table 2.

The PVOH/MMT endotherm shifted to the higher temperature values. The transition started at lower temperatures and ended at higher temperatures. It can be concluded that both values of $T_{m}$ and $\chi^{\text {DSC }}$ were very significantly increased for PVOH/MMT films. As it can be seen, $T_{m}$ was $273.1^{\circ} \mathrm{C}$; but $\chi^{\mathrm{DSC}}$ was $85.3 \%$ compared to $226.5^{\circ} \mathrm{C}$ and 


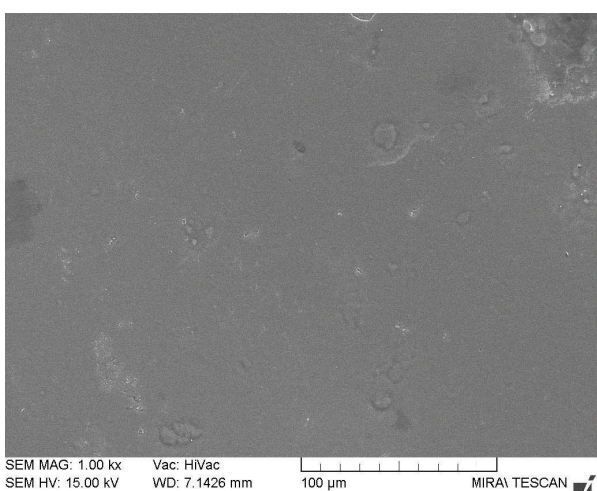

(a)



(c)

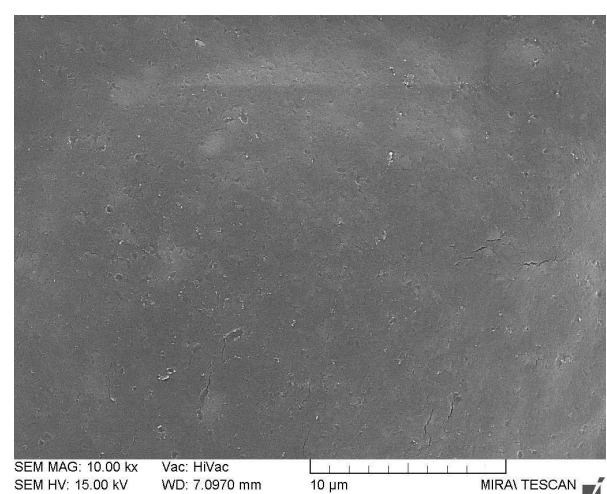

(b)

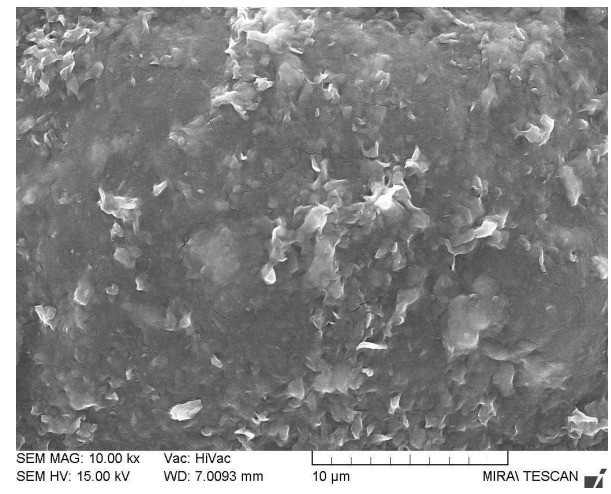

(d)

FIGURE 5: (a, b) SEM micrographs of PVOH/MMT film down surface; (c, d) SEM micrographs of PVOH/MMT films up surface.

44.9\% for initial PVOH correspondingly. Observed behavior also could be attributed to the nucleation effect of MMT layers and changes of quality and quantity in the polymer crystalline structure, and FTIR showed strong interaction in the interphase between PVOH and MMT $[42,43]$. Crystalline phase content for PVOH/MMT is two times higher than for initial PVOH. However, more perfect crystalline structure was also formed during PVOH and MMT LbL deposition, which corresponded well to the observed increase of $T_{m}$.

Scanning electron microscopy was used to test uniformity of surface and cross section of the prepared LbL film. The first deposited layer on the glass substrate was $\mathrm{PVOH}$ polymer. The surface that contacted the glass was shown in Figures 5(a) and 5(b). The surface looked very smooth and flat in different magnifications. In the comparison, Figures 5(c) and 5(d) showed the upper surface with the absorbed MMT layers in which homogeny and dense covered the surface.

Atomic force microscopy (AFM) examinations of tapping mode at different resolutions of the deposited films surface also verified dense coverage of the MMT layer (see Figure 6). Micrographs also demonstrated dense and high homogeneity structure of deposited MMT layer.

SEM micrographs of PVOH/MMT film cross section revealed layered structure with high lamina orientation of PVOH and MMT layers (Figure 7). MMT elementary platelets had coplanar spatial orientation. The film could be characterized by dense structure and uniform thickness. The observed thickness of the film cross sections was $3.0 \pm 0.5 \mu \mathrm{m}$. The measured thickness of double layer was about $35-50 \mathrm{~nm}$.

To understand the difference between the mechanisms of the reinforcement, the mechanical properties of $\mathrm{LbL}$ film of PVOH/MMT were compared with data of the nanocomposite of $\mathrm{PVOH} / \mathrm{MMT}^{*}$, which was prepared by conventional solution casting (Table 2). It is well known that the solution preparation of nanoclay-polymer nanocomposites acquires the possibility of macromolecules to penetrate into the platelet interlayer and promotes development of intercalated (stacked) or delaminated (exfoliated) structure of the nanocomposite $[18,19]$. Such nanocomposites can demonstrate good tensile property improvements. The conventional nanocomposite of $\mathrm{PVOH} / \mathrm{MMT}^{*}$ is characterized only by relatively low (about 1.5 times) improvements in elasticity and strength $(\sigma=80.2 \mathrm{MPa} ; E=3.2 \mathrm{GPa})$, because reinforcing efficiency (aspect ratio) decreases due to possible stacking of the nanoparticles. The total interactions intensity at the polymer-nanoparticle interface also decreases with agglomeration of the nanoparticles in the polymer matrix $[18,19]$.

In comparison, the mechanical properties for PVOH/ MMT LbL film showed two times higher strength $\sigma=$ 150.2 $\mathrm{MPa}$ and ten times higher modulus of elasticity $E=$ 11.2 $\mathrm{GPa}$ when compared with pure PVOH polymer $(\sigma=$ 85.1 MPa; $E=1.9 \mathrm{GPa}$ ). SEM micrographs (Figure 7) testified that PVOH/MMT film had a structure of the laminate, 

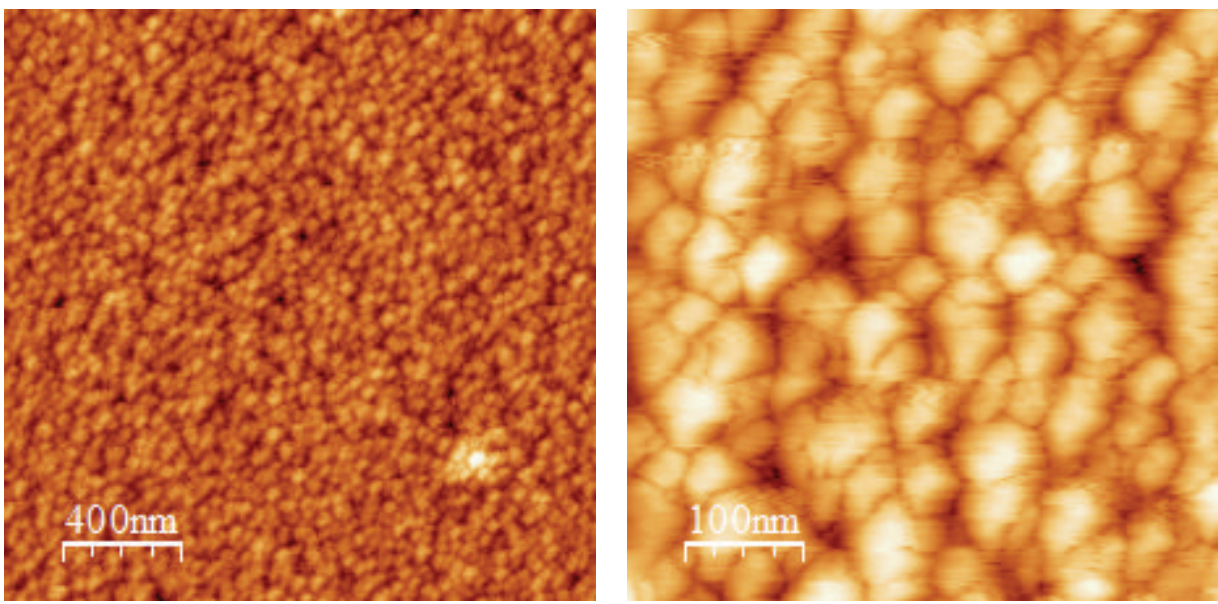

Figure 6: AFM phase images of PVOH/MMT film surface.



(a)



(b)

FIGURE 7: SEM micrographs of cross section of a 130-double-layer PVOH/MMT film at different magnifications (a, b).

which consisted of coplanar layers of MMT and PVOH. MMT layers acted as reinforcement with very large aspect ratio and the modulus of elasticity of about $175 \mathrm{GPa}$ [45]. $\mathrm{PVOH}$ and MMT were bound through formation of strong hydrogen bonds. It was testified by FTIR tests. As a result, very dense network of bonds at the components interface can be developed. The polymer consisted mainly (about $69-85 \%)$ of the strong and dense crystalline phase [29]. It also contributed to the total increase of the stiffness of the PVOH/MMT LbL deposited film.

\section{Conclusions}

PVOH/MMT film was prepared by LbL deposition method. PVOH/MMT film consisted of polymer and MMT coplanar layers. The resulting PVOH/MMT film was found to be strong and highly crystalline. Mechanical properties of $\mathrm{PVOH} / \mathrm{MMT}$ were superior to the initial polymer and traditional nanocomposite. Formation of high crystalline polymer and hydrogen bonding interactions between the MMT and $\mathrm{PVOH}$ also enhanced the strength and stiffness properties of the obtained PVOH/MMT nanocomposite. Concluding, it should be noted that the degree of crystallinity was verified by the use of three different approaches: WAXD, DSC, and FT-IR. The received crystallinity values were in the range of $69-85 \%$.

\section{Conflict of Interests}

The authors declare that there is no conflict of interests regarding the publication of this paper.

\section{Acknowledgment}

Support of this work was provided by the Riga Technical University through the scientific research Project ZP-2013/18.

\section{References}

[1] G. Decher, "Fuzzy nanoassemblies: toward layered polymeric multicomposites," Science, vol. 277, no. 5330, pp. 1232-1237, 1997.

[2] P. Podsiadlo, B. S. Shim, and N. A. Kotov, "Polymer/clay and polymer/carbon nanotube hybrid organic-inorganic multilayered composites made by sequential layering of nanometer scale films," Coordination Chemistry Reviews, vol. 253, no. 23-24, pp. 2835-2851, 2009. 
[3] E. Kharlampieva, V. Kozlovskaya, J. Chan, J. F. Ankner, and V. V. Tsukruk, "Spin-assisted layer-by-layer assembly: variation of stratification as studied with neutron reflectivity," Langmuir, vol. 25, no. 24, pp. 14017-14024, 2009.

[4] X. Li, G. Zhang, X. Bai et al., "Highly conducting graphene sheets and Langmuir-Blodgett films," Nature Nanotechnology, vol. 3, no. 9, pp. 538-542, 2008.

[5] S. Chen, "Langmuir-Blodgett fabrication of two-dimensional robust cross-linked nanoparticle assemblies," Langmuir, vol. 17, no. 9, pp. 2878-2884, 2001.

[6] H. Wei, N. Ma, F. Shi, Z. Wang, and X. Zhang, "Artificial nacre by alternating preparation of layer-by-layer polymer films and $\mathrm{CaCO}_{3}$ strata," Chemistry of Materials, vol. 19, no. 8, pp. 19741978, 2007.

[7] P. Podsiadlo, L. Sui, Y. Elkasabi et al., "Layer-by-layer assembled films of cellulose nanowires with antireflective properties," Langmuir, vol. 23, no. 15, pp. 7901-7906, 2007.

[8] X. Wang, K. Gao, Z. Shao, X. Peng, X. Wu, and F. Wang, "Layerby-Layer assembled hybrid multilayer thin film electrodes based on transparent cellulose nanofibers paper for flexible supercapacitors applications," Journal of Power Sources, vol. 249, pp. 148-155, 2014.

[9] N. G. Sahoo, S. Rana, J. W. Cho, L. Li, and S. H. Chan, "Polymer nanocomposites based on functionalized carbon nanotubes," Progress in Polymer Science, vol. 35, no. 7, pp. 837-867, 2010.

[10] S. K. Swain and I. Jena, "Polymer/carbon nanotube nanocomposites: a novel material," Asian Journal of Chemistry, vol. 22, no. 1, pp. 1-15, 2010.

[11] Z. Tang and N. A. Kotov, "One-dimensional assemblies of nanoparticles: preparation, properties, and promise," Advanced Materials, vol. 17, no. 8, pp. 951-962, 2005.

[12] D. M. Fernandes, D. Julião, C. Pereira, D. Ananias, S. S. Balula, and C. Freire, "Hybrid layer-by-layer films based on lanthanidebridged silicotungstates and poly(ethylenimine)," Colloids and Surfaces A: Physicochemical and Engineering Aspects, vol. 415, pp. 302-309, 2012.

[13] G. Zotti, B. Vercelli, and A. Berlin, "Monolayers and multilayers of conjugated polymers as nanosized electronic components," Accounts of Chemical Research, vol. 41, no. 9, pp. 1098-1109, 2008.

[14] S.-C. Wang, J. Yang, X.-Y. Zhou, and J. Li, "Layer-by-layer assembled sandwich-like carbon nanotubes/graphene oxide composite as high-performance electrodes for lithium-ion batteries," International Journal of Electrochemical Science, vol. 8, no. 7, pp. 9692-9703, 2013.

[15] E. Detsri and S. T. Dubas, "Layer-by-layer deposition of cationic and anionic carbon nanotubes into thin films with improved electrical properties," Colloids and Surfaces A: Physicochemical and Engineering Aspects, vol. 444, pp. 89-94, 2014.

[16] Y. Dou, X. Liu, M. Shao, J. Han, and M. Wei, "Flexible and transparent free-standing films with enhanced magnetic and luminescent anisotropy," Journal of Materials Chemistry A, vol. 1, no. 15, pp. 4786-4792, 2013.

[17] J. Gong, X. Han, X. Zhu, and Z. Guan, "Layer-by-layer assembled multilayer films of exfoliated layered double hydroxide and carboxymethyl- $\beta$-cyclodextrin for selective capacitive sensing of acephatemet," Biosensors and Bioelectronics, vol. 61, pp. 379385, 2014.

[18] M. Alexandre and P. Dubois, "Polymer-layered silicate nanocomposites: preparation, properties and uses of a new class of materials," Materials Science and Engineering R: Reports, vol. 28, no. 1, pp. 1-63, 2000.
[19] S. Pavlidou and C. D. Papaspyrides, "A review on polymerlayered silicate nanocomposites," Progress in Polymer Science (Oxford), vol. 33, no. 12, pp. 1119-1198, 2008.

[20] C. M. Andres, M. L. Fox, and N. A. Kotov, "Traversing material scales: macroscale LBL-assembled nanocomposites with microscale inverted colloidal crystal architecture," Chemistry of Materials, vol. 24, no. 1, pp. 9-11, 2012.

[21] P. Podsiadlo, E. M. Arruda, E. Kheng et al., "LBL assembled laminates with hierarchical organization from nano-to microscale: high-toughness nanomaterials and deformation imaging," ACS Nano, vol. 3, no. 6, pp. 1564-1572, 2009.

[22] H. Sehaqui, J. Kochumalayil, A. Liu, T. Zimmermann, and L. A. Berglund, "Multifunctional nanoclay hybrids of high toughness, thermal, and barrier performances," ACS Applied Materials and Interfaces, vol. 5, no. 15, pp. 7613-7620, 2013.

[23] H.-B. Yao, Z.-H. Tan, H.-Y. Fang, and S.-H. Yu, "Artificial nacrelike bionanocomposite films from the self-assembly of chitosanmontmorillonite hybrid building blocks," Angewandte Chemie International Edition, vol. 49, no. 52, pp. 10127-10131, 2010.

[24] Y. Shu, P. Yin, J. Wang, B. Liang, H. Wang, and L. Guo, "Bioinspired nacre-like heparin/layered double hydroxide film with superior mechanical, fire-shielding, and UV-blocking properties," Industrial and Engineering Chemistry Research, vol. 53, no. 10, pp. 3820-3826, 2014.

[25] P. Podsiadlo, A. K. Kaushik, E. M. Arruda et al., "Ultrastrong and stiff layered polymer nanocomposites," Science, vol. 318, no. 5847, pp. 80-83, 2007.

[26] L. J. Bonderer, A. R. Studart, and L. J. Gauckler, "Bioinspired design and assembly of platelet reinforced polymer films," Science, vol. 319, no. 5866, pp. 1069-1073, 2008.

[27] H. B. Yao, H. Y. Fang, Z. H. Tan, L. H. Wu, and S. H. $\mathrm{Yu}$, "Biologically inspired, strong, transparent, and functional layered organic-inorganic hybrid films," Angewandte ChemieInternational Edition, vol. 49, no. 12, pp. 2140-2145, 2010.

[28] Y. Li, X. Wang, and J. Sun, "Layer-by-layer assembly for rapid fabrication of thick polymeric films," Chemical Society Reviews, vol. 41, no. 18, pp. 5998-6009, 2012.

[29] K. E. Strawhecker and E. Manias, "Structure and properties of poly(vinyl alcohol) $/ \mathrm{Na}^{+}$montmorillonite nanocomposites," Chemistry of Materials, vol. 12, no. 10, pp. 2943-2949, 2000.

[30] D. Chen, X. Wang, T. Liu, X. Wang, and J. Li, "Electrically conductive poly(vinyl alcohol) hybrid films containing graphene and layered double hydroxide fabricated via layer-by-layer selfassembly," ACS Applied Materials and Interfaces, vol. 2, no. 7, pp. 2005-2011, 2010.

[31] L. Zeng, T. S. Zhao, and Y. S. Li, "Synthesis and characterization of crosslinked poly (vinyl alcohol)/layered double hydroxide composite polymer membranes for alkaline direct ethanol fuel cells," International Journal of Hydrogen Energy, vol. 37, no. 23, pp. 18425-18432, 2012.

[32] Z. Mo and H. Zhang, "The degree of crystallinity in polymers by Wide-Angle X-Ray Diffraction (WAXD)," Journal of Macromolecular Science C: Polymer Reviews, vol. 35, no. 4, pp. 555-580, 1995.

[33] S. Rabiej and A. Wlochowicz, "SAXS and WAXS investigations of the crystallinity in polymers," Die Angewandte Makromolekulare Chemie, vol. 175, no. 1, pp. 81-97, 1990.

[34] S.-S. Wong, S. A. Altinkaya, and S. K. Mallapragada, "Crystallization of poly(vinyl alcohol) during solvent removal: infrared characterization and mathematical modeling," Journal of Polymer Science Part B: Polymer Physics, vol. 45, no. 8, pp. 930-935, 2007. 
[35] J. F. Kenney and G. W. Willcockson, "Structure-Property relationships of poly(vinyl alcohol). III. Relationships between stereo-regularity, crystallinity, and water resistance in poly(vinyl alcohol)," Journal of Polymer Science A-1: Polymer Chemistry, vol. 4, no. 3, pp. 679-698, 1966.

[36] Z. Mo, X. Huang, and H. Zhang, "The degree of crystallinity of multicomponent polymers by waxd," Chinese Journal of Polymer Science, vol. 12, no. 4, pp. 296-301, 1994.

[37] N. A. Peppas, "Infrared spectroscopy of semicrystalline poly(vinyl alcohol) networks," Die Makromolekulare Chemie, vol. 178, no. 2, pp. 595-601, 1977.

[38] X. M. Shi, J. Zhang, J. Jin, and S. J. Chen, "Non-isothermal crystallization and melting of ethylene-vinyl acetate copolymers with different vinyl acetate contents," Express Polymer Letters, vol. 2, no. 9, pp. 623-629, 2008.

[39] S. K. Mallapragada and N. A. Peppas, "Dissolution mechanism of semicrystalline poly(vinyl alcohol) in water," Journal of Polymer Science Part B: Polymer Physics, vol. 34, no. 7, pp. 13391346, 1996.

[40] S. Gaidukov, Polymer nanocomposites filled with nanoscale placoid particles of montmorillonite [Doctoral thesis], Riga Technical University, 2008.

[41] W. J. Choi, S. H. Kim, Y. Jin Kim, and S. C. Kim, "Synthesis of chain-extended organifier and properties of polyurethane/clay nanocomposites," Polymer, vol. 45, no. 17, pp. 6045-6057, 2004.

[42] M. Ramanathan and S. B. Darling, "Mesoscale morphologies in polymer thin films," Progress in Polymer Science, vol. 36, no. 6, pp. 793-812, 2011.

[43] Y. X. Liu and E. Q. Chen, "Polymer crystallization of ultrathin films on solid substrates," Coordination Chemistry Reviews, vol. 254, no. 9-10, pp. 1011-1037, 2010.

[44] C. H. Manoratne, R. M. G. Rajapakse, and M. A. K. L. Dissanayake, "Ionic conductivity of poly(ethylene oxide) (PEO)montmorillonite (MMT) nanocomposites prepared by intercalation from aqueous medium," International Journal of Electrochemical Science, vol. 1, no. 1, pp. 32-46, 2006.

[45] R. D. Maksimov, S. Gaidukovs, M. Kalnins, J. Zicans, and E. Plume, "A nanocomposite based on a styrene-acrylate copolymer and native montmorillonite clay 2. Modeling the elastic properties," Mechanics of Composite Materials, vol. 42, no. 2, pp. 163-172, 2006. 



Submit your manuscripts at http://www.hindawi.com
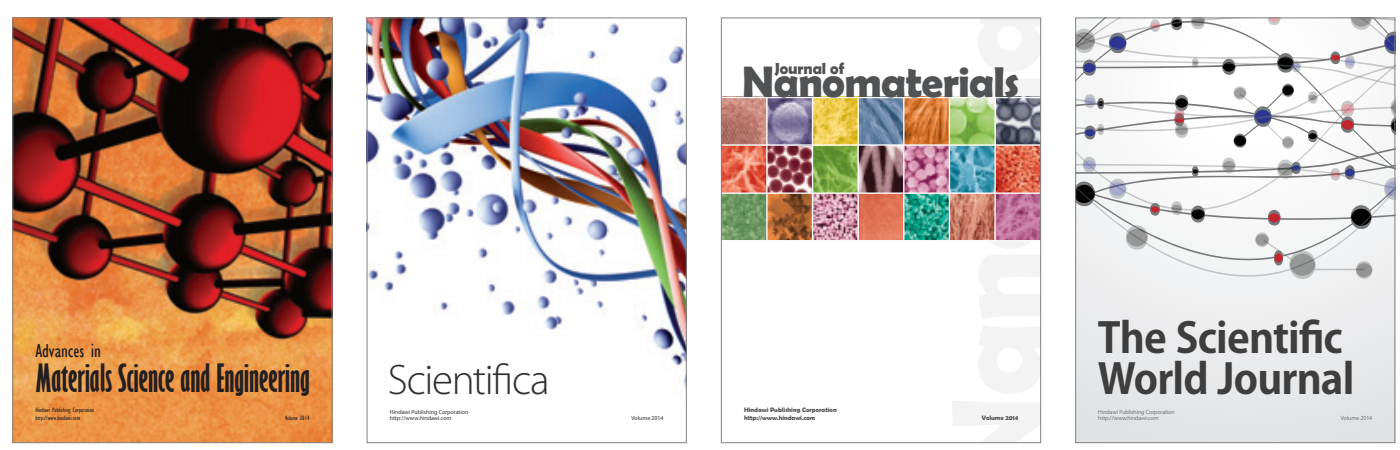

\section{The Scientific World Journal}
